\title{
Neural guidance molecules regulate vascular remodeling and vessel navigation
}

\author{
Anne Eichmann, ${ }^{1,4}$ Taija Makinen, ${ }^{2}$ and Kari Alitalo ${ }^{3,5}$ \\ ${ }^{1}$ Institut National de la Santé et de la Recherche Médicale U36, Collège de France, 75005 Paris, France; \\ ${ }^{2}$ Max-Planck-Institute of Neurobiology, Department of Molecular Neurobiology, 82152 Martinsried, Germany; \\ ${ }^{3}$ Molecular/Cancer Biology Laboratory and Ludwig Institute for Cancer Research, Biomedicum Helsinki, Helsinki University \\ Central Hospital, University of Helsinki, 00014 Helsinki, Finland
}

The development of the embryonic blood vascular and lymphatic systems requires the coordinated action of several transcription factors and growth factors that target endothelial and periendothelial cells. However, according to recent studies, the precise "wiring" of the vascular system does not occur without an ordered series of guidance decisions involving several molecules initially discovered for axons in the nervous system, including ephrins, netrins, slits, and semaphorins. Here, we summarize the new advances in our understanding of the roles of these axonal pathfinding molecules in vascular remodeling and vessel guidance, indicating that neuronal axons and vessel sprouts use common molecular mechanisms for navigation in the body.

During development, differentiation of mesodermal precursor cells leads to the formation of the primary vascular plexus, which is progressively remodeled into a highly branched hierarchical vascular tree composed of arteries and veins (Risau 1997). The establishment of arterial-venous identity plays a critical role in the development of a normal blood vessel network. The specification of angioblasts into arterial or venous lineages is genetically determined and occurs already before the onset of blood circulation. The early steps of arterial-venous differentiation require the activation of vascular endothelial growth factor (VEGF) and Notch signaling pathways (Lawson et al. 2001, 2002). Genetic loss-offunction experiments in mice and zebrafish have shown that signaling mediated by Notch, as well as by activin receptor-like kinase 1, regulates arterial-venous differentiation by inducing the expression of arterial-specific and suppressing venous-specific genes (Urness et al. 2000; Lawson et al. 2001; Duarte et al. 2004; Gale et al. 2004; Krebs et al. 2004) Failure in the specification of arterial

[Keywords: Angiogenesis; lymphangiogenesis; ephrin; netrin; semaphorin; slit]

Corresponding authors.

${ }^{4}$ E-MAIL anne.eichmann@college-de-france.fr; FAX 33-1-4427-1691.

${ }^{5}$ E-MAIL kari.alitalo@helskinki.fi; FAX 358-9-1912-5510.

Article and publication are at http://www.genesdev.org/cgi/doi/10.1101/ gad.1305405. and venous identities or in the establishment of the arterio-venous boundaries leads to vascular fusions and dysplasia.

Embryonic vessel formation is also subject to intense remodeling, with entire vessel tracts being removed or reconnected throughout development. Embryonic endothelial cells can change their repertoire of arterial-venous-specific genes during remodeling as shown in the chick embryo yolk sac; alterations in perfusion can transform arteries into veins and vice-versa, both morphologically (the direction of blood flow changes) and genetically (arterial markers are replaced by venous ones) (le Noble et al. 2004). Hemodynamic forces are thus a determining factor in shaping the vascular patterns. Oxygenation of the embryo's cells also influences vessel patterning; regions of hypoxia constitute strong attractive signals and regions of high-oxygen concentration constitute repellents (Carmeliet 2003). Are these global patterning mechanisms sufficient to establish the highly stereotyped branching patterns observed in the developing vascular systems? Vessel branches penetrating different organs and the limbs form at designated sites, suggesting that the precise wiring of the vascular system is achieved by an ordered series of guidance decisions. Clues to the molecular nature of these guidance cues came from the anatomical similarities of the vascular and nervous systems; like blood vessels, nerves are complex branched systems and the patterning of blood vessels and nerves is often congruent in peripheral tissues (Mukouyama et al. 2002, 2005; Bates et al. 2003). Recent experiments have shown that specialized cells located at the extremities of capillary sprouts, termed tip cells, regulate blood-vessel branching (Gerhardt et al. 2003). Tip cells are highly similar to the growth cones of developing axons, as they extend numerous filopodia that explore their environment. In the developing mouse retina, tip cells regulate extension of the capillary sprouts in response to gradients of VEGF produced by retinal astrocytes (Gerhardt et al. 2003). Emerging evidence summarized below suggests that axon growth cones and capillary tip cells use common signaling cues including netrins, slits, and semaphorins to regulate their guidance. 
The development of lymphatic vessels starts from the blood vasculature after its establishment. A subset of venous endothelial cells commits to the lymphatic endothelial cell lineage and sprouts from the major veins in the jugular and perimesonephric area to form sac-like structures, from which the vessels grow further by centrifugal sprouting. The homeodomain transcription factor Proxl is required for the initial specification (Wigle and Oliver 1999; Wigle et al. 2002), while activation of VEGF receptor-3 by VEGF-C is essential for the migration and proliferation of lymphatic endothelial cells (Karkkainen et al. 2004). Interestingly, Proxl is the mammalian homolog of Drosophila prospero, a key gene for the development of the nervous system, which specifies multiple aspects from the early formation of the embryonic central nervous system to the formation of larval and adult sensory organs (Chia et al. 2001). However, compared with the knowledge of the molecular mechanisms regulating blood vascular remodeling, the processes involved in the maturation of the lymphatic system and the importance of the remodeling for the establishment of a functional lymphatic vasculature are largely unknown.

\section{Ephrins and Eph receptors provide signals for the maturation and remodeling of blood and lymphatic vessels}

Neural guidance molecules of the ephrin/Eph ligand-receptor family have been recently implicated in the regulation of lymphatic vessel remodeling, as well as in the maturation and remodeling of the arterial-venous plexus. During the development of the nervous system, ephrins provide repulsive guidance signals for Eph receptor-expressing axonal growth cones and migrating neural crest cells (for review, see Klein 2004). In addition, these molecules have an important role during formation of the blood vasculature. Ephrin-Eph-mediated signaling functions bidirectionally; after cell contact-mediated binding of the ligand, the Eph receptor tyrosine kinases become clustered and phosphorylated, which leads to recruitment of signaling effectors and activation of signaltransduction cascades. However, the transmembrane ephrinB ligands also have cytoplasmic domains with intrinsic signaling capacity. After binding to the Eph receptors, they can be phosphorylated in their tyrosine residues by Src-family kinases (Palmer et al. 2002) or by activated receptor tyrosine kinases, such as PDGF receptor or Tie-2 (Bruckner et al. 1997; Adams et al. 1999). In addition, ephrinB ligands have a C-terminal motif for the binding of PDZ-domain containing proteins (Torres et al. 1998; Bruckner et al. 1999; Lin et al. 1999).

EphrinB2 expression specifically in the arterial and EphB4 in the venous endothelium provide one of the earliest known molecular distinction between arteries and veins. Disruption of either gene leads to failure in the remodeling of the primary capillary plexus and in the formation of major embryonic vessels (Wang et al. 1998; Adams et al. 1999; Gerety et al. 1999). While ephrin/Eph signaling appears not to be essential for the initial speci- fication of endothelial cell fates, interaction between ephrinB2 and EphB4 at the arterial-venous interface is required to provide repulsion signals for the establishment and maintenance of boundaries between these vessels, reminiscent of the repulsive guidance of axonal growth cones (Wang et al. 1998; Adams et al. 1999). Furthermore, ephrin/Eph interaction between mesenchymal and endothelial cells is involved in mediating repulsive guidance for migrating endothelial cells during the formation of intersomitic vessels (Adams et al. 1999; Helbling et al. 2000). However, ephrinB-Eph interaction can also induce sprouting of endothelial cells and therefore provide attraction signals for these cells (Adams et al. 1999; Zhang et al. 2001; Palmer et al. 2002; Fuller et al. 2003). It remains to be elucidated whether ephrins and Ephs also have direct positive function in blood-vessel guidance in vivo, and in which biological processes such guidance is involved. The observation that EphrinB2-deficient embryos show defective vascularization of the nervous system, which normally occurs by angiogenic sprouting from adjacent vessels, suggests a role for ephrinB2 as an inducer of capillary sprouting in vivo (Adams et al. 1999). In addition, certain Ephs and ephrins are expressed and up-regulated at sites of active neovascularization, e.g., in the blood-vessel endothelia during tumor invasion, further suggesting a positive role in endothelial cell migration. The functional readout of ephrinEph interaction, i.e., whether it has an attractive or repellent role, may depend on cellular context and on the involvement of other signaling components, such as growth-factor receptors.

Recently, ephrin-Eph signaling was also implicated in lymphatic development. When the lymphatic vasculature develops from embryonic blood circulation, polarized expression of the homeobox transcription factor Prox1 is initiated in a subpopulation of endothelial cells in certain embryonic veins, under the influence of an as yet unknown signal (Wigle and Oliver 1999). Prox1-positive endothelial cells up-regulate a number of lymphatic endothelial specific markers, bud from the cardinal veins, and migrate to form primary lymph sacs, from which lymphatic capillaries sprout to form the primary lymphatic plexus. Further development of lymphatic vessels include remodeling and maturation to form a superficial lymphatic capillary network and deeper collecting lymphatic vessels, which are characterized by the presence of a basement membrane, mural cells, and valves. PDZ-dependent signaling via ephrinB2 was shown to be important for the formation of luminal valves and for the remodeling of the lymphatic vasculature into a hierarchically organized vessel network consisting of lymphatic capillaries and collecting lymphatic vessels (Makinen et al. 2005). Interestingly, although blood vascular development appeared normal in these mice, post-natal development of lymphatic vessels, which involves remodeling of the primitive lymphatic vascular plexus via the formation of new sprouts, was specifically disturbed (Fig. 1). Similar to the blood vasculature, where the tip cell filopodia guide endothelial cell migration and elongation, the initiation of lym- 


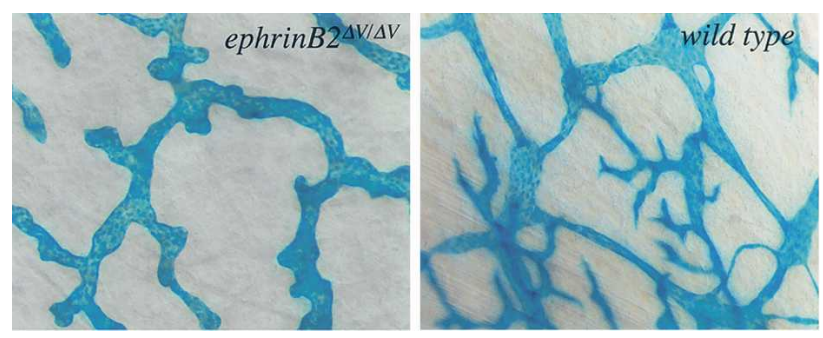

Figure 1. Dermal lymphatic vessels fail to sprout in mice lacking the PDZ-binding site of ephrinB2. At post-natal day 2, the primary lymphatic capillary plexus is remodeled by the formation of new sprouts. This remodeling process is deficient in mice lacking the PDZ-binding site in ephrinB2. Adapted with permission from Makinen et al. (2005).

phatic endothelial cell sprouting coincided with the formation of filopodial extensions from the vessels and with subsequent elongation of the sprouting cell. However, in the ephrinB2 mutant mice, the sprouting was disturbed, which resulted in blunt-ended protrusions, suggesting a role for ephrinB2 reverse signaling during the elongation and guidance of sprouting lymphatic endothelial cells (Makinen et al. 2005).

\section{Netrins as repulsive vessel guidance cues}

Netrins are a family of secreted laminin-related molecules highly conserved throughout evolution (Hedgecock et al. 1990; Ishii et al. 1992; Serafini et al. 1994). Three members of the netrin gene family have been identified in mammals: netrin-1, netrin-3, and Bnetrin/netrin-4 (Serafini et al. 1996; Van Raay et al. 1997; Wang et al. 1999; Koch et al. 2000; Yin et al. 2000). Netrins are bifunctional guidance cues, attracting some axons, while repelling others (for review, see Dickson 2002; Dickson and Keleman 2002). Genetic evidence and in vitro studies have shown that Netrins are secreted from cells at the ventral midline of the central nervous system and attract commissural axons toward the midline. Netrins can, however, also repel certain axons, including the trochlear motor axons in vertebrates (Colamarino and Tessier-Lavigne 1995). Attraction and repulsion are mediated by binding to receptors of the deleted in colorectal cancer (DCC) and uncoordinated 5 (UNC5) families (Fig. 2). The DCC family consists of DCC and neogenin (Chan et al. 1996; Keino-Masu et al. 1996), while the UNC5 family comprises four members, UNC5A to UNC5D (Leung-Hagesteijn et al. 1992; Ackerman et al. 1997; Leonardo et al. 1997; Engelkamp 2002). Axon attraction is mediated by the DCC receptors (Fazeli et al. 1997), while repulsion requires signaling through the UNC5 receptor homodimers or with UNC5-DCC receptor heterodimers (Hedgecock et al. 1990; Hong et al. 1999; Keleman and Dickson 2001). Netrin-mediated attraction can also be converted to repulsion by altering the level of intracellular cyclic nucleotides (Nishiyama et al. 2003), a common theme for most axon guidance cues.

In addition to their well-demonstrated role in axon guidance, the widespread expression of Netrins and their receptors outside the nervous system suggests additional roles for these ligand/receptor pairs during morphogenesis. Indeed, Netrins and their receptors have been implicated in other developmental processes, including regulation of apoptosis (for review, see Arakawa 2004), lung branching morphogenesis (Liu et al. 2004) and mammary gland development (Srinivasan et al. 2003). In addition, Netrins have recently been implicated in angiogenesis. Park et al. (2004) have reported in vitro experiments that suggest a promitogenic and promigratory effect of Netrin-1 on primary endothelial and smooth muscle cells. Antibodies directed against the neogenin receptor blocked smooth muscle-cell migration induced by Netrin-1. In contrast, Lu et al. (2004) have provided genetic evidence for a negative role of Netrins in vessel guidance, suggesting that Netrins may act as attractants or repellents in both the nervous and the vascular system. $\mathrm{Lu}$ and colleagues have shown that among the Netrin receptors, the UNC5B receptor is selectively expressed in the vascular system, with very little expression in the nervous system during early mouse development. UNC5B expression in the vasculature is observed in arteries, a subset of capillaries, and endothelial tip cells. Inactivation of the Unc5b gene in mice led to embryonic lethality associated with significantly increased branching of capillaries in the central nervous system. Vessel branching was selectively affected in Unc5b-deficient mice, as neither changes in arterio-venous marker expression, nor in vessel-wall assembly or endothelial-cell proliferation and apoptosis could be detected.

Treatment of endothelial cells with the ligand Netrin-1 resulted in tip cell filopodial retraction (Fig. 3), and this effect was abolished in Unc5b-deficient mice, suggesting that Netrin-1 mediates repulsive guidance of capillary tip cells through UNC5B signaling. Morpholino knockdown of the zebrafish ortholog of $U n c 5 b$ or its ligand Netrin-1 $a$ also led to aberrant pathfinding of the intersegmental vessels (ISVs). Interestingly, the phenotype affected a particular step of vessel guidance. ISV sprouting into the intersegmental space and initial dorsal migration were unaffected. Aberrant pathfinding occurred at the level of the horizontal myoseptum (which normally expresses the highest levels of Netrin-1a), where instead of extending dorsally, ISVs in both Netrin$1 a$ and $U n c 5 b$ morphants deviated laterally (Lu et al. 2004). These results suggest that the Netrin-UNC5B ligand/receptor pair may act at specific guideposts for developing vessels, which, in zebrafish, are localized at the level of the horizontal myoseptum.

\section{Slits in vessel development}

Slit was originally identified in Drosophila as an extracellular cue to guide axon pathfinding (Rothberg et al. 1990). In mammals, three Slit family members, Slit-1, Slit-2, and Slit-3, are expressed in the nervous system midline, with Slit-2 and Slit-3 also being expressed on other cell types (Holmes et al. 1998; Itoh et al. 1998; 
Figure 2. Schematic structure of neural guidance molecules implicated in angiogenesis. $(A)$ Ligands (top) and receptors (bottom) directly implicated in angiogenic remodeling and guidance, including ephrinB2, EphB4, Netrin, UNC5B, Slit, Robo4, and Sema3E and its receptor PlexinD1. For EphrinB, Netrin, and Slit ligands, only one member of a larger family is shown, as detailed in the text. For Eph and Robo receptors, only one family member is represented, while expression of additional members of both families in endothelial cells has been reported (Adams et al. 1999; Fuller et al. 2003; Wang et al. 2003). Abbreviations for domains are from SMART (http://smart. embl-heidelberg.de). Abbreviations modified from Dickson (2002). (B) Simplified model of signaling through Neuropilin receptor complexes. (Left) Functional association of Nrp-1 and Nrp-2 receptors with Plexin-signaling receptors transduce Sema3 signals. Nrp-1 is known to bind Sema3A and Sema3C, while Nrp-2 binds Sema3C and Sema3F. This mode of signaling is thought to signal axon repulsion in the nervous system (Pasterkamp and Kolodkin 2003) and during cardiac remodeling (Gitler et al. 2004). (Right) In the vascu

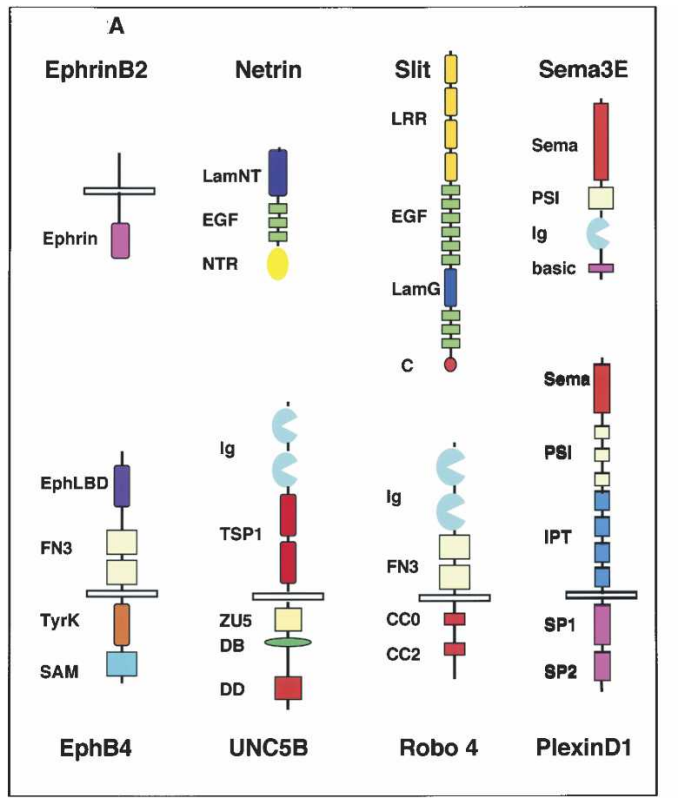

B

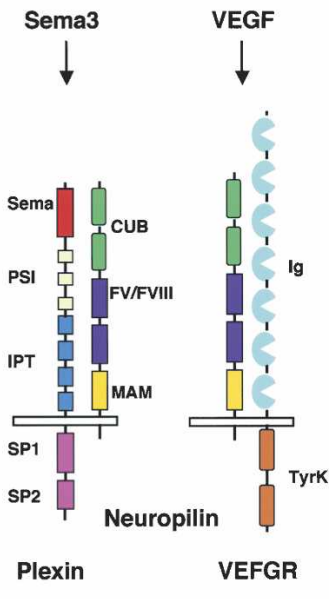
signals. Nrp-1 was shown to bind different VEGF family members, as well as the VEGF165 isoform (Neufeld et al. 2002). Nrp-2 binds some of these VEGF family members as well as VEGF-C (Karkkainen et al. 2001). Signal transduction of VEGF-165 through VEGFR-2 is enhanced in the presence of Nrp-1, as shown in stably transfected PAE cells (Miao et al. 1999). VEGF-165 signaling through Nrp-1 was also shown to control migration of the cell bodies of the facial nerve (Schwarz et al. 2004), but the coreceptor implicated has not been identified.

Piper et al. 2000; Marillat et al. 2002). Midline Slits act as chemo-repellents, preventing ipsilateral axons from crossing the midline and commissural axons from recrossing it (Kidd et al. 1999; Long et al. 2004). Slit actions are mediated by binding to Roundabout (Robo) receptors (Fig. 2). Four Robo receptors, Robo-1-Robo-4, are known in mammals (Kidd et al. 1998a,b; Huminiecki et al. 2002), with Robo-4 (also referred to as Magic Roundabout) being structurally divergent from the other proteins. Similar to Netrins, Slits are also implicated in developmental processes outside of the nervous system, notably in leukocyte trafficking (Wu et al. 2001), kidney induction (Grieshammer et al. 2004), and in muscle pre-
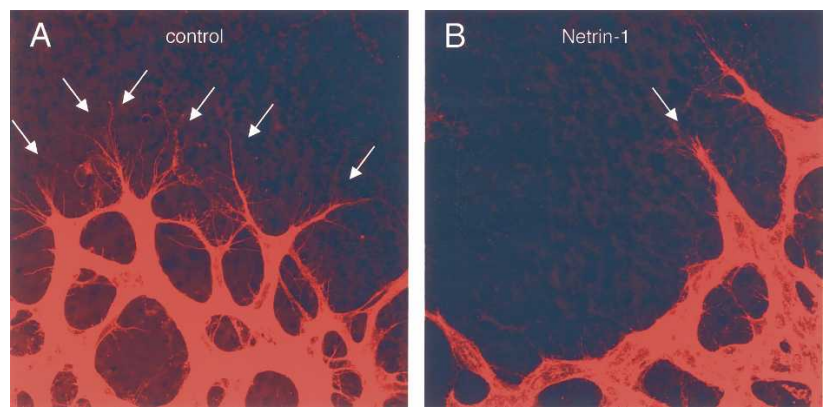

Figure 3. Effect of Netrin-1 on endothelial tip cell filopodia. $(A, B)$ Confocal images of post-natal mouse retina stained with isolectinB4. (A) Endothelial tip cells at the periphery of the retina extend numerous filopodia (arrows). (B) After intraocular injection of Netrin-1 protein, most filopodia have retracted (arrow). cursor cell migration in Drosophila (Kramer et al. 2001). In the latter process, Slit initially acts as a repellent on early phase migrating muscle precursors, but switches its action to an attractant during the late phase of myofiber attachment to the epidermis (Kramer et al. 2001).

Several recent studies have also implicated Slits and their receptors in angiogenesis. Notably, Robo4 is expressed in developing ISVs in mouse embryos (Park et al. 2003) and primary human endothelial cells, including microvascular endothelial cells and umbilical vein endothelial cells (Suchting et al. 2005). Results on Robo4 binding to Slits are controversial; while one study reports binding of Robo4 to Slit-2 (Park et al. 2003), another report fails to observe binding of this receptor to any Slit protein (Suchting et al. 2005). In vitro studies also yield controversial results; in one study, exposure of microvascular endothelial cells to Slit-2 inhibited endothelial cell migration (Park et al. 2003). Conversely, Slit-2 treatment of umbilical vein endothelial cells, which were shown to express Robol, stimulated endothelial cell chemotaxis in vitro and tumor angiogenesis in vivo (Wang et al. 2003). The role of the Slit family and their Robo receptors in vascular guidance thus remains to be clarified.

\section{Repulsive tip cell guidance by Semaphorin 3E-PlexinD1 signaling}

Semaphorins comprise a large family of phylogenetically conserved secreted and membrane-bound proteins. More 
than 20 semaphorins are known to date, all characterized by a large $\mathrm{N}$-terminal semaphorin domain, which mediates receptor binding. Eight semaphorin subclasses are distinguished based on structural features and sequence similarities; subclasses 1 and 2 comprise invertebrate semaphorins, subclasses 3-7 represent vertebrate semaphorins, and subclass $\mathrm{V}$ comprises viral semaphorins (for review, see Pasterkamp and Kolodkin 2003). Semaphorins have been shown to function as potent axon chemorepellents, both by in vitro and by genetic studies in Drosophila and mouse. As observed with Netrins, alteration of the cytosolic cyclic nucleotide level can convert repulsion to attraction (for review, see Fiore and Puschel 2003). Semaphorins thus appear to represent bifunctional guidance cues, endowed with attractive or repulsive activities, similar to Netrins and Slits (for review, see Dickson 2002; Huber et al. 2003). Semaphorins mediate their actions by binding to two major receptor families, Plexins and Neuropilins (Nrps) (Fig. 2). To date, two Nrps and nine Plexins have been identified in mammals (for review, see Fujisawa 2004). Neuropilins also bind members of the VEGF growth-factor family (see below). Invertebrate semaphorins, vertebrate membraneassociated semaphorins, and viral semaphorins directly associate with plexins, while vertebrate class 3 -secreted semaphorins (Sema3s) bind receptor complexes consisting of Nrps as binding subunits and plexins as signal transducers (Pasterkamp and Kolodkin 2003; Fujisawa 2004).

An exception to this rule is Sema3E, which directly binds to PlexinD1, independently of Nrps (Fig. 2; Gu et al. 2004). The PlexinD1-Sema3E interaction was recently shown to mediate repulsive vessel guidance. PlexinD1 is expressed in developing blood-vessel endothelial cells (van der Zwaag et al. 2002). Loss-of-function of plexinD1 in zebrafish and mouse embryos leads to perturbed vessel pathfinding (Gitler et al. 2004; Gu et al. 2004; TorresVazquez et al. 2004). In zebrafish, loss-of-function mutations of plexinD1 are responsible for the out-of-bounds (obd) mutation (Childs et al. 2002; Torres-Vazquez et al. 2004). As observed in Netrin $1 a$ and in Unc5b mutant embryos, assembly of the dorsal aorta and cardinal vein, artery-vein specification, and endothelial-cell proliferation are normal in obd fish. However, selection of the appropriate site of sprouting of the ISVs from the dorsal aorta is perturbed in obd; ISVs do not respect anterioposterior intersomitic boundaries and erroneously branch throughout the somites, particularly in the ventral trunk. Thus, obd selectively perturbs ISV sprout-site selection and initial dorsal extension of the forefront migrating endothelial cell. Compared with the phenotype of Netrin1a or Unc5b mutant fish, obd thus appears to act at a different guidepost.

In mouse embryos, knockout of plexinD1 also results in intersomitic vessel patterning defects (Gitler et al. 2004; Gu et al. 2004). PlexinD1-deficient mouse mutants show exuberant branching of intersomitic blood vessels and loss of the normal segmented blood-vessel pattern. The ligand involved in PlexinD1 signaling appears to be Sema3E (Gu et al. 2004). Sema3E is expressed in the caudal region of the somite, immediately adjacent to the intersomitic blood vessels expressing PlexinD1. Sema3E and plexinD1 mouse mutant embryos exhibit a highly similar vascular phenotype (Gu et al. 2004). As mentioned above, this phenotype does not depend on Nrps; double-mutant mice deficient in Nrp-2 and in the Nrp-1 Sema3-binding site showed normal segmental blood vessel patterns. COS cell binding and collapse assays showed that Sema3E directly signals through PlexinD1, independently of the presence of Nrps. Blood vessels avoid chick embryo somites that overexpress Sema3E, suggesting that this molecule mediates endothelial cell repulsion. Thus, Sema3E directly signals through PlexinD1 to restrict blood vessel growth to the intersomitic boundaries (Gu et al. 2004).

\section{Neuropilin receptors and the patterning of the vascular and nervous systems}

The two related Nrp receptors Nrp-1 and Nrp-2 are expressed in both the nervous and vascular systems, bind two classes of structurally unrelated ligands, secreted Sema3s as well as certain VEGF isoforms, and associate with two different types of receptors to mediate signal transduction (for review, see Neufeld et al. 2002; Pasterkamp and Kolodkin 2003). These observations place the Nrps at the heart of the cross-talk between the nervous and the vascular systems and raise the question as to how they function. In the nervous system, Sema3 binding to a complex of Nrp and Plexin receptors leads to axonal growth cone collapse (Pasterkamp and Kolodkin 2003). In endothelial cells, signal transduction is mediated via VEGF receptor-2 (VEGFR-2), as shown by the enhanced migratory response of endothelial cells to VEGF165 in vitro in the presence of both receptors (Soker et al. 1998; Miao et al. 1999). In this setting, Sema3A and VEGF165 compete with each other for binding to Nrp-1, and Sema3A binding to Nrp-1 in the presence of VEGFR-2 can inhibit VEGF-dependent angiogenesis (Miao et al. 1999). These results suggest that Sema3s could influence endothelial cell migration indirectly by competing with VEGF for Nrp binding. Consistent with this idea, several recent studies have reported a role for Sema3 signaling in angiogenesis. For instance, Sema3A is expressed by endothelial cells of developing blood vessels in chick and mice, and inhibits endothelial migration by interfering with integrin function (Bates et al. 2003; Serini et al. 2003). Sema3F inhibits tumor angiogenesis and metastasis in mouse xenograft models (Bielenberg et al. 2004; Kessler et al. 2004). However, these studies could not exclude alternative possibilities for Sema3 action on vascular cells, including a direct action by binding to Nrp-Plexin complexes, or action through other signaling pathways. Gu et al. (2003) performed genetic manipulation in mice to selectively disrupt Nrp-1 interactions with Sema3, while retaining VEGF binding. Neural development was severely affected in these mice, while overall vascular development was normal, indicating that Sema3/Nrp signaling is dispensable for vascular development. In contrast, endothelial-specific ablation of the $n r p 1$ gene led to severe mal- 
formations of the vascular system, consistent with the idea that VEGF binding to Nrp-1 is responsible for its effects on vascular development (Gu et al. 2003).

In the vascular system, both Nrps are coexpressed in yolk-sac endothelial cells during vasculogenesis (Herzog et al. 2001). Combined knockouts for both Nrp-1 and Nrp-2 receptor lead to vasculogenesis defects and failure to assemble the primary vascular plexus (Takashima et al. 2002). At later stages, Nrp-1 is preferentially expressed in arterial endothelial cells, while Nrp-2 labels venous and lymphatic endothelium (Herzog et al. 2001; Moyon et al. 2001; Yuan et al. 2002). In the vascular system, nrp2 deficiency selectively affects the development of small lymphatic vessels and capillaries (Yuan et al. 2002). Conventional, as well as endothelial-specific ablation of nrp1 is embryonic lethal, the mice exhibit cardiac defects as well as defects in vessel branching in the outflow tract and the central nervous system (Kawasaki et al. 1999; Gu et al. 2003; Gerhardt et al. 2004). Vessel-branching defects in nrp1-deficient mice point to a role in tip cell guidance, but mouse mutants lacking the Nrp-1-binding VEGF164 isoform show distinct vessel patterning defects (Ruhrberg et al. 2002), suggesting a more selective requirement of $\mathrm{Nrp}-1$ during vessel branching that remains to be clarified. Consistent with its arterial-specific expression, however, Nrp-1 has recently been implicated in arterial differentiation. Arteries of the embryonic dermis, unlike the veins, are aligned with peripheral nerves, and arterial differentiation is dependent on the production of VEGF by sensory and motoneurons and Schwann cells and on the expression of Nrp-1 in arterial endothelium (Mukouyama et al. 2005). In agreement, absence of peripheral sensory nerves or Schwann cells prevents proper arteriogenesis, while a disorganized network of nerves leads to alignment of arteries with misrouted axons (Mukouyama et al. 2002).

Increasing attention has been given to a possible role for VEGF as a guidance cue in the nervous system. VEGFR-2, the main signal transducer for VEGF, is expressed by neurons and growth cones of regenerating axons (Sondell et al. 2000). In vitro experiments have shown that VEGF/VEGFR-2 signaling can promote axonal outgrowth (Sondell et al. 1999), although the normality of mice deficient of VEGFR-2 in neuronal cells suggests that VEGF/VEGFR-2 signaling has no significant autocrine role in CNS development (Haigh et al. 2003). VEGF is also expressed by ependymal cells at sites of neurogenesis and can enhance self-renewal and proliferation of neurons and neuronal stem cells. Clear genetic evidence for a direct role of VEGF in neuronal development comes from a recent study focusing on facial branchiomotor neurons in the hindbrain of mouse embryos (Schwarz et al. 2004). The cell bodies (somata) of these neurons are born in the hindbrain segment rhombomere 4 and extend axons into the second branchial arch to form the seventh cranial nerve. Simultaneously, the somata of the facial branchiomotor neurons themselves also move in a caudal direction into rhombomere 6 to form the motor nuclei of the seventh cranial nerve. Guidance of motor axons is dependent on signaling through Sema3A and its receptor Nrp-1, as axon fasciculation does not occur in the absence of either ligand or receptor. Migration of the somata of these neurons is also arrested in Nrp-1 mutants. Although both Nrp-1 ligands Sema3A and Sema3C are expressed in the hindbrain in a spatiotemporal pattern consistent with a role in facial branchiomotor soma migration, this migration occurred normally in the absence of either ligand. In addition, mouse embryos genetically engineered to express a Nrp-1 receptor that cannot bind Sema3 also showed normal soma migration, suggesting that the movement of somata is regulated differently from the movement of axons. Interestingly, soma movement of facial branchiomotor neurons requires VEGF164 (Schwarz et al. 2004). In mice that do not express this isoform, soma migration shows pathfinding defects reminiscent of those seen in $n r p 1^{-1-}$ mice. Pathfinding of somata thus does not depend on the presence of axons or on the formation of a vascular network, and the picture emerging from these studies is that guidance depends on the binding of two types of ligands to the Nrp-1 receptor; Sema3A binding triggers signals that regulate axon guidance, while VEGF164 binding triggers signals that regulate soma migration. While these experiments provide evidence for a role of VEGF in neuronal guidance, the molecular mechanisms responsible for VEGF164 and Sema3A signaling through Nrp-1 in neurons and in endothelial cells remain to be clarified.

\section{Acknowledgments}

A.E. is supported by grants from INSERM (Avenir), Ministère de la recherche (ACI); K.A. and A.E. are supported by European Community (LSHG-CT-2004-503573). T.M. is supported by post-doctoral fellowships from the European Molecular Biology Organization and the Human Frontier Science Program Organization. We apologize for not citing all relevant work due to space restrictions.

\section{References}

Ackerman, S.L., Kozak, L.P., Przyborski, S.A., Rund, L.A., Boyer, B.B., and Knowles, B.B. 1997. The mouse rostral cerebellar malformation gene encodes an UNC-5-like protein. Nature 386: 838-842.

Adams, R.H., Wilkinson, G.A., Weiss, C., Diella, F., Gale, N.W., Deutsch, U., Risau, W., and Klein, R. 1999. Roles of ephrinB ligands and EphB receptors in cardiovascular development: Demarcation of arterial/venous domains, vascular morphogenesis, and sprouting angiogenesis. Genes \& Dev. 13: 295306.

Arakawa, H. 2004. Netrin-1 and its receptors in tumorigenesis. Nat. Rev. Cancer 4: 978-987.

Bates, D., Taylor, G.I., Minichiello, J., Farlie, P., Cichowitz, A., Watson, N., Klagsbrun, M., Mamluk, R., and Newgreen, D.F. 2003. Neurovascular congruence results from a shared patterning mechanism that utilizes Semaphorin3A and Neuropilin-1. Dev. Biol. 255: 77-98.

Bielenberg, D.R., Hida, Y., Shimizu, A., Kaipainen, A., Kreuter, M., Kim, C.C., and Klagsbrun, M. 2004. Semaphorin 3F, a chemorepulsant for endothelial cells, induces a poorly vascularized, encapsulated, nonmetastatic tumor phenotype. $J$. Clin. Invest. 114: 1260-1271. 
Bruckner, K., Pasquale, E.B., and Klein, R. 1997. Tyrosine phosphorylation of transmembrane ligands for Eph receptors. Science 275: 1640-1643.

Bruckner, K., Pablo Labrador, J., Scheiffele, P., Herb, A., Seeburg, P.H., and Klein, R. 1999. EphrinB ligands recruit GRIP family PDZ adaptor proteins into raft membrane microdomains. Neuron 22: 511-524.

Carmeliet, P. 2003. Blood vessels and nerves: Common signals, pathways and diseases. Nat. Rev. Genet. 4: 710-720.

Chan, S.S., Zheng, H., Su, M.W., Wilk, R., Killeen, M.T., Hedgecock, E.M., and Culotti, J.G. 1996. UNC-40, a C. elegans homolog of DCC (Deleted in Colorectal Cancer), is required in motile cells responding to UNC-6 netrin cues. Cell 87: 187-195.

Chia, W., Cai, Y., Morin, X., Tio, M., Udolph, G., Yu, F., and Yang, X. 2001. The cell cycle machinery and asymmetric cell division of neural progenitors in the Drosophila embryonic central nervous system. Novartis Found. Symp. 237: 139151; discussion 151-163.

Childs, S., Chen, J.N., Garrity, D.M., and Fishman, M.C. 2002. Patterning of angiogenesis in the zebrafish embryo. Development 129: 973-982.

Colamarino, S.A. and Tessier-Lavigne, M. 1995. The axonal chemoattractant netrin-1 is also a chemorepellent for trochlear motor axons. Cell 81: 621-629.

Dickson, B.J. 2002. Molecular mechanisms of axon guidance. Science 298: 1959-1964.

Dickson, B.J. and Keleman, K. 2002. Netrins. Curr. Biol. 12: R154-R155.

Duarte, A., Hirashima, M., Benedito, R., Trindade, A., Diniz, P., Bekman, E., Costa, L., Henrique, D., and Rossant, J. 2004. Dosage-sensitive requirement for mouse Dll4 in artery development. Genes \& Dev. 18: 2474-2478.

Engelkamp, D. 2002. Cloning of three mouse Unc5 genes and their expression patterns at mid-gestation. Mech. Dev. 118: 191-197.

Fazeli, A., Dickinson, S.L., Hermiston, M.L., Tighe, R.V., Steen, R.G., Small, C.G., Stoeckli, E.T., Keino-Masu, K., Masu, M., Rayburn, H., et al. 1997. Phenotype of mice lacking functional Deleted in colorectal cancer (Dcc) gene. Nature 386: 796-804.

Fiore, R. and Puschel, A.W. 2003. The function of semaphorins during nervous system development. Front. Biosci. 8: s484s499.

Fujisawa, H. 2004. Discovery of semaphorin receptors, neuropilin and plexin, and their functions in neural development. $J$. Neurobiol. 59: 24-33.

Fuller, T., Korff, T., Kilian, A., Dandekar, G., and Augustin, H.G. 2003. Forward EphB4 signaling in endothelial cells controls cellular repulsion and segregation from ephrinB2 positive cells. J. Cell. Sci. 116: 2461-2470.

Gale, N.W., Dominguez, M.G., Noguera, I., Pan, L., Hughes, V., Valenzuela, D.M., Murphy, A.J., Adams, N.C., Lin, H.C., Holash, J., et al. 2004. Haploinsufficiency of $\delta$-like 4 ligand results in embryonic lethality due to major defects in arterial and vascular development. Proc. Natl. Acad. Sci. 101: 15949-15954.

Gerety, S.S., Wang, H.U., Chen, Z.F., and Anderson, D.J. 1999. Symmetrical mutant phenotypes of the receptor EphB4 and its specific transmembrane ligand ephrin-B2 in cardiovascular development. Mol. Cell 4: 403-414.

Gerhardt, H., Golding, M., Fruttiger, M., Ruhrberg, C., Lundkvist, A., Abramsson, A., Jeltsch, M., Mitchell, C., Alitalo, K., Shima, D., et al. 2003. VEGF guides angiogenic sprouting utilizing endothelial tip cell filopodia. I. Cell Biol. 161: $1163-1177$.
Gerhardt, H., Ruhrberg, C., Abramsson, A., Fujisawa, H., Shima, D., and Betsholtz, C. 2004. Neuropilin-1 is required for endothelial tip cell guidance in the developing central nervous system. Dev. Dyn. 231: 503-509.

Gitler, A.D., Lu, M.M., and Epstein, J.A. 2004. PlexinD1 and semaphorin signaling are required in endothelial cells for cardiovascular development. Dev. Cell 7: 107-116.

Grieshammer, U., Le, M., Plump, A.S., Wang, F., Tessier-Lavigne, M., and Martin, G.R. 2004. SLIT2-mediated ROBO2 signaling restricts kidney induction to a single site. Dev. Cell 6: 709-717.

Gu, C., Rodriguez, E.R., Reimert, D.V., Shu, T., Fritzsch, B., Richards, L.J., Kolodkin, A.L., and Ginty, D.D. 2003. Neuropilin-1 conveys semaphorin and VEGF signaling during neural and cardiovascular development. Dev. Cell 5: 45-57.

Gu, C., Yoshida, Y., Livet, J., Reimert, D.V., Mann, F., Merte, J., Henderson, C.E., Jessell, T.M., Kolodkin, A.L., and Ginty, D.D. 2004. Semaphorin 3E and Plexin-D1 control vascular pattern independently of neuropilins. Science 307: 265-268.

Haigh, J.J., Morelli, P.I., Gerhardt, H., Haigh, K., Tsien, J., Damert, A., Miquerol, L., Muhlner, U., Klein, R., Ferrara, N., et al. 2003. Cortical and retinal defects caused by dosagedependent reductions in VEGF-A paracrine signaling. Dev. Biol. 262: 225-241.

Hedgecock, E.M., Culotti, J.G., and Hall, D.H. 1990. The unc-5, unc-6, and unc-40 genes guide circumferential migrations of pioneer axons and mesodermal cells on the epidermis in $C$. elegans. Neuron 4: 61-85.

Helbling, P.M., Saulnier, D.M., and Brandli, A.W. 2000. The receptor tyrosine kinase EphB4 and ephrin-B ligands restrict angiogenic growth of embryonic veins in Xenopus laevis. Development 127: 269-278.

Herzog, Y., Kalcheim, C., Kahane, N., Reshef, R., and Neufeld, G. 2001. Differential expression of neuropilin-1 and neuropilin-2 in arteries and veins. Mech. Dev. 109: 115-119.

Holmes, G.P., Negus, K., Burridge, L., Raman, S., Algar, E., Yamada, T., and Little, M.H. 1998. Distinct but overlapping expression patterns of two vertebrate slit homologs implies functional roles in CNS development and organogenesis. Mech. Dev. 79: 57-72.

Hong, K., Hinck, L., Nishiyama, M., Poo, M.M., Tessier-Lavigne, M., and Stein, E. 1999. A ligand-gated association between cytoplasmic domains of UNC5 and DCC family receptors converts netrin-induced growth cone attraction to repulsion. Cell 97: 927-941.

Huber, A.B., Kolodkin, A.L., Ginty, D.D., and Cloutier, J.F. 2003. Signaling at the growth cone: Ligand-receptor complexes and the control of axon growth and guidance. Annu. Rev. Neurosci. 26: 509-563.

Huminiecki, L., Gorn, M., Suchting, S., Poulsom, R., and Bicknell, R. 2002. Magic roundabout is a new member of the roundabout receptor family that is endothelial specific and expressed at sites of active angiogenesis. Genomics 79: 547552.

Ishii, N., Wadsworth, W.G., Stern, B.D., Culotti, J.G., and Hedgecock, E.M. 1992. UNC-6, a laminin-related protein, guides cell and pioneer axon migrations in C. elegans. Neuron 9: 873-881.

Itoh, A., Miyabayashi, T., Ohno, M., and Sakano, S. 1998. Cloning and expressions of three mammalian homologues of Drosophila slit suggest possible roles for Slit in the formation and maintenance of the nervous system. Brain Res. Mol. Brain Res. 62: 175-186.

Karkkainen, M.J., Saaristo, A., Jussila, L., Karila, K.A., Lawrence, E.C., Pajusola, K., Bueler, H., Eichmann, A., Kauppinen, R., Kettunen, M.I., et al. 2001. A model for gene 
therapy of human hereditary lymphedema. Proc. Natl. Acad. Sci. 98: 12677-12682.

Karkkainen, M.J., Haiko, P., Sainio, K., Partanen, J., Taipale, J., Petrova, T.V., Jeltsch, M., Jackson, D.G., Talikka, M., Rauvala, H., et al. 2004. Vascular endothelial growth factor $\mathrm{C}$ is required for sprouting of the first lymphatic vessels from embryonic veins. Nat. Immunol. 5: 74-80.

Kawasaki, T., Kitsukawa, T., Bekku, Y., Matsuda, Y., Sanbo, M., Yagi, T., and Fujisawa, H. 1999. A requirement for neuropilin-1 in embryonic vessel formation. Development 126: 4895-4902.

Keino-Masu, K., Masu, M., Hinck, L., Leonardo, E.D., Chan, S.S., Culotti, J.G., and Tessier-Lavigne, M. 1996. Deleted in Colorectal Cancer (DCC) encodes a netrin receptor. Cell 87: 175-185.

Keleman, K. and Dickson, B.J. 2001. Short- and long-range repulsion by the Drosophila Unc5 netrin receptor. Neuron 32: 605-617.

Kessler, O., Shraga-Heled, N., Lange, T., Gutmann-Raviv, N., Sabo, E., Baruch, L., Machluf, M., and Neufeld, G. 2004. Semaphorin-3F is an inhibitor of tumor angiogenesis. Cancer Res. 64: 1008-1015.

Kidd, T., Brose, K., Mitchell, K.J., Fetter, R.D., Tessier-Lavigne, M., Goodman, C.S., and Tear, G. 1998a. Roundabout controls axon crossing of the CNS midline and defines a novel subfamily of evolutionarily conserved guidance receptors. Cell 92: 205-215.

Kidd, T., Russell, C., Goodman, C.S., and Tear, G. 1998b. Dosage-sensitive and complementary functions of roundabout and commissureless control axon crossing of the CNS midline. Neuron 20: 25-33.

Kidd, T., Bland, K.S., and Goodman, C.S. 1999. Slit is the midline repellent for the robo receptor in Drosophila. Cell 96: 785-794.

Klein, R. 2004. Eph/ephrin signaling in morphogenesis, neural development and plasticity. Curr. Opin. Cell. Biol. 16: 580589.

Koch, M., Murrell, J.R., Hunter, D.D., Olson, P.F., Jin, W., Keene, D.R., Brunken, W.J., and Burgeson, R.E. 2000. A novel member of the netrin family, $\beta$-netrin, shares homology with the $\beta$ chain of laminin: Identification, expression, and functional characterization. J. Cell. Biol. 151: 221234.

Kramer, S.G., Kidd, T., Simpson, J.H., and Goodman, C.S. 2001. Switching repulsion to attraction: Changing responses to slit during transition in mesoderm migration. Science 292: 737 740.

Krebs, L.T., Shutter, J.R., Tanigaki, K., Honjo, T., Stark, K.L., and Gridley, T. 2004. Haploinsufficient lethality and formation of arteriovenous malformations in Notch pathway mutants. Genes \& Dev. 18: 2469-2473.

Lawson, N.D., Scheer, N., Pham, V.N., Kim, C.H., Chitnis, A.B., Campos-Ortega, J.A., and Weinstein, B.M. 2001. Notch signaling is required for arterial-venous differentiation during embryonic vascular development. Development 128: 36753683.

Lawson, N.D., Vogel, A.M., and Weinstein, B.M. 2002. sonic hedgehog and vascular endothelial growth factor act upstream of the Notch pathway during arterial endothelial differentiation. Dev. Cell 3: 127-136.

le Noble, F., Moyon, D., Pardanaud, L., Yuan, L., Djonov, V., Matthijsen, R., Breant, C., Fleury, V., and Eichmann, A. 2004. Flow regulates arterial-venous differentiation in the chick embryo yolk sac. Development 131: 361-375.

Leonardo, E.D., Hinck, L., Masu, M., Keino-Masu, K., Ackerman, S.L., and Tessier-Lavigne, M. 1997. Vertebrate homo- logues of C. elegans UNC-5 are candidate netrin receptors. Nature 386: 833-838.

Leung-Hagesteijn, C., Spence, A.M., Stern, B.D., Zhou, Y., Su, M.W., Hedgecock, E.M., and Culotti, J.G. 1992. UNC-5, a transmembrane protein with immunoglobulin and thrombospondin type 1 domains, guides cell and pioneer axon migrations in C. elegans. Cell 71: 289-299.

Lin, D., Gish, G.D., Songyang, Z., and Pawson, T. 1999. The carboxyl terminus of B class ephrins constitutes a PDZ domain binding motif. J. Biol. Chem. 274: 3726-3733.

Liu, Y., Stein, E., Oliver, T., Li, Y., Brunken, W.J., Koch, M., Tessier-Lavigne, M., and Hogan, B.L. 2004. Novel role for Netrins in regulating epithelial behavior during lung branching morphogenesis. Curr. Biol. 14: 897-905.

Long, H., Sabatier, C., Ma, L., Plump, A., Yuan, W., Ornitz, D.M., Tamada, A., Murakami, F., Goodman, C.S., and Tessier-Lavigne, M. 2004. Conserved roles for Slit and Robo proteins in midline commissural axon guidance. Neuron 42: 213-223.

Lu, X., Le Noble, F., Yuan, L., Jiang, Q., De Lafarge, B., Sugiyama, D., Breant, C., Claes, F., De Smet, F., Thomas, J.L., et al. 2004. The netrin receptor UNC5B mediates guidance events controlling morphogenesis of the vascular system. Nature 432: 179-186.

Makinen, T., Adams, R.H., Bailey, J., Lu, Q., Ziemiecki, A., Alitalo, K., Klein, R., and Wilkinson, G.A. 2005. PDZ interaction site in ephrinB2 is required for the remodeling of lymphatic vasculature. Genes \& Dev. 19: 397-410.

Marillat, V., Cases, O., Nguyen-Ba-Charvet, K.T., Tessier-Lavigne, M., Sotelo, C., and Chedotal, A. 2002. Spatiotemporal expression patterns of slit and robo genes in the rat brain. $J$. Comp. Neurol. 442: 130-155.

Miao, H.Q., Soker, S., Feiner, L., Alonso, J.L., Raper, J.A., and Klagsbrun, M. 1999. Neuropilin-1 mediates collapsin-1/ semaphorin III inhibition of endothelial cell motility: Functional competition of collapsin-1 and vascular endothelial growth factor-165. J. Cell. Biol. 146: 233-242.

Moyon, D., Pardanaud, L., Yuan, L., Breant, C., and Eichmann, A. 2001. Plasticity of endothelial cells during arterial-venous differentiation in the avian embryo. Development 128: 3359-3370.

Mukouyama, Y.S., Shin, D., Britsch, S., Taniguchi, M., and Anderson, D.J. 2002. Sensory nerves determine the pattern of arterial differentiation and blood vessel branching in the skin. Cell 109: 693-705.

Mukouyama, Y.S., Gerber, H.P., Ferrara, N., Gu, C., and Anderson, D.J. 2005. Peripheral nerve-derived VEGF promotes arterial differentiation via neuropilin 1-mediated positive feedback. Development 132: 941-952.

Neufeld, G., Cohen, T., Shraga, N., Lange, T., Kessler, O., and Herzog, Y. 2002. The neuropilins: Multifunctional semaphorin and VEGF receptors that modulate axon guidance and angiogenesis. Trends Cardiovasc. Med. 12: 13-19.

Nishiyama, M., Hoshino, A., Tsai, L., Henley, J.R., Goshima, Y., Tessier-Lavigne, M., Poo, M.M., and Hong, K. 2003. Cyclic AMP/GMP-dependent modulation of $\mathrm{Ca} 2+$ channels sets the polarity of nerve growth-cone turning. Nature 424: 990 995.

Palmer, A., Zimmer, M., Erdmann, K.S., Eulenburg, V., Porthin, A., Heumann, R., Deutsch, U., and Klein, R. 2002. EphrinB phosphorylation and reverse signaling: Regulation by Src kinases and PTP-BL phosphatase. Mol. Cell 9: 725-737.

Park, K.W., Morrison, C.M., Sorensen, L.K., Jones, C.A., Rao, Y., Chien, C.B., Wu, J.Y., Urness, L.D., and Li, D.Y. 2003. Robo4 is a vascular-specific receptor that inhibits endothelial migration. Dev. Biol. 261: 251-267. 
Park, K.W., Crouse, D., Lee, M., Karnik, S.K., Sorensen, L.K., Murphy, K.J., Kuo, C.J., and Li, D.Y. 2004. The axonal attractant Netrin-1 is an angiogenic factor. Proc. Natl. Acad. Sci. 101: 16210-16215.

Pasterkamp, R.J. and Kolodkin, A.L. 2003. Semaphorin junction: Making tracks toward neural connectivity. Curr. Opin. Neurobiol. 13: 79-89.

Piper, M., Georgas, K., Yamada, T., and Little, M. 2000. Expression of the vertebrate Slit gene family and their putative receptors, the Robo genes, in the developing murine kidney. Mech. Dev. 94: 213-217.

Risau, W. 1997. Mechanisms of angiogenesis. Nature 386: 671674.

Rothberg, J.M., Jacobs, J.R., Goodman, C.S., and Artavanis-Tsakonas, S. 1990. slit: An extracellular protein necessary for development of midline glia and commissural axon pathways contains both EGF and LRR domains. Genes \& Dev. 4: $2169-2187$.

Ruhrberg, C., Gerhardt, H., Golding, M., Watson, R., Ioannidou, S., Fujisawa, H., Betsholtz, C., and Shima, D.T. 2002. Spatially restricted patterning cues provided by heparin-binding VEGF-A control blood vessel branching morphogenesis. Genes \& Dev. 16: 2684-2698.

Schwarz, Q., Gu, C., Fujisawa, H., Sabelko, K., Gertsenstein, M., Nagy, A., Taniguchi, M., Kolodkin, A.L., Ginty, D.D., Shima, D.T., et al. 2004. Vascular endothelial growth factor controls neuronal migration and cooperates with Sema3A to pattern distinct compartments of the facial nerve. Genes \& Dev. 18: 2822-2834.

Serafini, T., Kennedy, T.E., Galko, M.J., Mirzayan, C., Jessell, T.M., and Tessier-Lavigne, M. 1994. The netrins define a family of axon outgrowth-promoting proteins homologous to C. elegans UNC-6. Cell 78: 409-424.

Serafini, T., Colamarino, S.A., Leonardo, E.D., Wang, H., Beddington, R., Skarnes, W.C., and Tessier-Lavigne, M. 1996. Netrin-1 is required for commissural axon guidance in the developing vertebrate nervous system. Cell 87: 1001-1014.

Serini, G., Valdembri, D., Zanivan, S., Morterra, G., Burkhardt, C., Caccavari, F., Zammataro, L., Primo, L., Tamagnone, L., Logan, M., et al. 2003. Class 3 semaphorins control vascular morphogenesis by inhibiting integrin function. Nature 424: 391-397.

Soker, S., Takashima, S., Miao, H.Q., Neufeld, G., and Klagsbrun, M. 1998. Neuropilin-1 is expressed by endothelial and tumor cells as an isoform-specific receptor for vascular endothelial growth factor. Cell 92: 735-745.

Sondell, M., Lundborg, G., and Kanje, M. 1999. Vascular endothelial growth factor has neurotrophic activity and stimulates axonal outgrowth, enhancing cell survival and Schwann cell proliferation in the peripheral nervous system. J. Neurosci. 19: 5731-5740.

Sondell, M., Sundler, F., and Kanje, M. 2000. Vascular endothelial growth factor is a neurotrophic factor which stimulates axonal outgrowth through the flk-1 receptor. Eur. I. Neurosci. 12: 4243-4254.

Srinivasan, K., Strickland, P., Valdes, A., Shin, G.C., and Hinck, L. 2003. Netrin-1/neogenin interaction stabilizes multipotent progenitor cap cells during mammary gland morphogenesis. Dev. Cell 4: 371-382.

Suchting, S., Heal, P., Tahtis, K., Stewart, L.M., and Bicknell, R. 2005. Soluble Robo4 receptor inhibits in vivo angiogenesis and endothelial cell migration. Faseb J. 19: 121-123.

Takashima, S., Kitakaze, M., Asakura, M., Asanuma, H., Sanada, S., Tashiro, F., Niwa, H., Miyazaki Ji, J., Hirota, S., Kitamura, Y., et al. 2002. Targeting of both mouse neuropilin-1 and neuropilin-2 genes severely impairs developmental yolk sac and embryonic angiogenesis. Proc. Natl. Acad. Sci. 99: 3657-3662.

Torres, R., Firestein, B.L., Dong, H., Staudinger, J., Olson, E.N., Huganir, R.L., Bredt, D.S., Gale, N.W., and Yancopoulos, G.D. 1998. PDZ proteins bind, cluster, and synaptically colocalize with Eph receptors and their ephrin ligands. Neuron 21: 1453-1463.

Torres-Vazquez, J., Gitler, A.D., Fraser, S.D., Berk, J.D., Van, N.P., Fishman, M.C., Childs, S., Epstein, J.A., and Weinstein, B.M. 2004. Semaphorin-plexin signaling guides patterning of the developing vasculature. Dev. Cell 7: 117-123.

Urness, L.D., Sorensen, L.K., and Li, D.Y. 2000. Arteriovenous malformations in mice lacking activin receptor-like kinase1. Nat. Genet. 26: 328-331.

van der Zwaag, B., Hellemons, A.J., Leenders, W.P., Burbach, J.P., Brunner, H.G., Padberg, G.W., and Van Bokhoven, H. 2002. PLEXIN-D1, a novel plexin family member, is expressed in vascular endothelium and the central nervous system during mouse embryogenesis. Dev. Dyn. 225: 336-343.

Van Raay, T.J., Foskett, S.M., Connors, T.D., Klinger, K.W., Landes, G.M., and Burn, T.C. 1997. The NTN2L gene encoding a novel human netrin maps to the autosomal dominant polycystic kidney disease region on chromosome 16p13.3. Genomics 41: 279-282.

Wang, H.U., Chen, Z.F., and Anderson, D.J. 1998. Molecular distinction and angiogenic interaction between embryonic arteries and veins revealed by ephrin-B2 and its receptor EphB4. Cell 93: 741-753.

Wang, H., Copeland, N.G., Gilbert, D.J., Jenkins, N.A., and Tessier-Lavigne, M. 1999. Netrin-3, a mouse homolog of human NTN2L, is highly expressed in sensory ganglia and shows differential binding to netrin receptors. I. Neurosci. 19: 4938-4947.

Wang, B., Xiao, Y., Ding, B.B., Zhang, N., Yuan, X., Gui, L., Qian, K.X., Duan, S., Chen, Z., Rao, Y., et al. 2003. Induction of tumor angiogenesis by Slit-Robo signaling and inhibition of cancer growth by blocking Robo activity. Cancer Cell 4: 19-29.

Wigle, J.T. and Oliver, G. 1999. Proxl function is required for the development of the murine lymphatic system. Cell 98: 769-778.

Wigle, J.T., Harvey, N., Detmar, M., Lagutina, I., Grosveld, G., Gunn, M.D., Jackson, D.G., and Oliver, G. 2002. An essential role for Proxl in the induction of the lymphatic endothelial cell phenotype. EMBO J. 21: 1505-1513.

Wu, J.Y., Feng, L., Park, H.T., Havlioglu, N., Wen, L., Tang, H., Bacon, K.B., Jiang, Z., Zhang, X., and Rao, Y. 2001. The neuronal repellent Slit inhibits leukocyte chemotaxis induced by chemotactic factors. Nature 410: 948-952.

Yin, Y., Sanes, J.R., and Miner, J.H. 2000. Identification and expression of mouse netrin-4. Mech. Dev. 96: 115-119.

Yuan, L., Moyon, D., Pardanaud, L., Breant, C., Karkkainen, M.J., Alitalo, K., and Eichmann, A. 2002. Abnormal lymphatic vessel development in neuropilin 2 mutant mice. Development 129: 4797-4806.

Zhang, X.Q., Takakura, N., Oike, Y., Inada, T., Gale, N.W., Yancopoulos, G.D., and Suda, T. 2001. Stromal cells expressing ephrin-B2 promote the growth and sprouting of ephrinB2(+) endothelial cells. Blood 98: 1028-1037. 